\title{
Mitochondria-DNA copy-number and incident venous thromboembolism among middle-aged women: a population-based cohort study
}

\author{
Peter Nymberg ${ }^{1}$ D $\cdot$ Ashfaque A. Memon ${ }^{1} \cdot$ Jan Sundquist ${ }^{1} \cdot$ Kristina Sundquist $^{1} \cdot$ Bengt Zöller $^{1}$
}

Accepted: 3 April 2021 / Published online: 15 April 2021

(c) The Author(s) 2021

\begin{abstract}
Venous thromboembolism (VTE) is the third most common cardiovascular disease. Low amount of mitochondrial DNA copy number (mtDNA-CN) has been associated with arterial cardiovascular disease (CVD) and reflects mitochondrial dysfunctions. However, whether mtDNA-CN is associated with VTE has not been determined. To examine the association between mtDNA-CN and incident VTE among middle-aged women. 6917 women aged 50-64 years, followed for 20 years in the Women's Health In the Lund Area (WHILA) study. DNA samples for mtDNA quantification were available from 2521 women. Quantification of mtDNA-CN was performed using a well-optimized droplet digital PCR method. After exclusions of women with anticoagulant treatment, women living in nursing homes, and women who were diagnosed with cancer, stroke, VTE, or coronary heart disease at baseline, a cohort of 2117 women remained for analysis. Cox regression was used to analyze the relationship between mtDNA-CN and time to VTE (hazard ratio $=\mathrm{HR}$ ). In total, 87 women were diagnosed with VTE during follow-up, corresponding to an incidence rate of 2.8 per 1000 person-years. Neither crude nor adjusted HR for mtDNA-CN were significantly associated with incident VTE. A sensitivity analysis with inclusion of excluded women did not change the results. MtDNA-CN was not significantly associated with VTE. The present study suggests that mtDNA$\mathrm{CN}$, reflecting mitochondrial dysfunction, should not be considered a biomarker that plays a major role for developing VTE. However, due to limited study size we may not exclude minor associations.
\end{abstract}

\begin{tabular}{ll}
\multicolumn{2}{l}{ Abbreviations } \\
VTE & Venous thromboembolism \\
CVD & Arterial cardiovascular disease \\
mtDNA-CN & Mitochondrial DNA \\
PE & Pulmonary embolism \\
DVT & Deep vein thrombosis \\
SBP & Systolic blood pressure \\
DBP & Diastolic blood pressure \\
WHILA & Women's Health In the Lund Area study \\
ddPCR & Optimized droplet digital PCR \\
SRH & Self-rated health \\
BMI & Body mass index \\
HR & Hazards ratio \\
FH & Family history
\end{tabular}

Peter Nymberg

peter.nymberg@med.lu.se

1 Center for Primary Health Care Research, Lund University/ Region Skåne, Skåne University Hospital Malmö, University Hospital, Jan Waldenströms gata 35, SE-205 02 Malmö, Sweden

\section{Highlights}

- This is the first study examining association between mtDNA-CN and incident VTE.

- mtDNA-CN is not associated with incident VTE.

- Low mtDNA-CN is not a major risk factor for VTE among middle-aged women.

\section{Introduction}

There are more than 200,000 new cases of venous thromboembolism (VTE) each year in the United States, with a corresponding mortality rate of about $30 \%$ within 30 days [1]. Among VTE survivors, 30\% develop recurrent VTE [1] and the increased mortality risk lasts up to 8 years after the first VTE event [1,2]. Arterial cardiovascular diseases (CVD) share several risk factors with VTE such as obesity, cancer, infections, oestrogens [3], smoking, and obstructive sleep apnea syndrome [4-6]. In addition to the shared risk, CVD and VTE predispose for each other, i.e., prevalent 
CVD increases the risk of incident VTE [7, 8]. Obesity, with an increased waist circumference, is also a risk factor for metabolic syndrome [9], which increases the risk for varicose veins, VTE, CVD, and diabetes type II [1, 10-14]. According to a systematic review [15] with a meta-analysis of the result from five articles with a total of 8252 cases and 20,904 controls, low amount of mitochondria DNA copy number ( $\mathrm{mtDNA}-\mathrm{CN})$ is a suggested risk indicator for CVDs. In previous studies, individuals with high BMI and metabolic syndrome have shown a low amount of mtDNA$\mathrm{CN}$ compared with healthy individuals [16, 17]. MtDNA-CN is also suggested to be a biomarker for aging where those with age-related diseases have lower amount of mtDNA-CN [18]. Poor self-rated health has been reported to be associated with lower levels of mtDNA-CN [19]. Poor self-rated health is also a predictor for incident CVD [20]. Lifestyle may also affect the levels of mtDNA-CN; current smoking is associated with lower amount of mtDNA-CN [21] and studies have suggested that high alcohol consumption may affect the levels of mtDNA-CN [22, 23]. In contrast, healthy lifestyle, such as regular physical activity, is associated with higher mtDNA-CN [24, 25]. Physical activity, in accordance with WHO recommendations, lowers risk for both CVD [26] and VTE [27, 28].

Since mtDNA-CN has been associated with CVD, and there are common risk factors that affect the amount of mtDNA-CN shared between both CVD and VTE, we hypothesize that low amount of mtDNA-CN also is associated with an increased VTE risk.

The main aim of this cohort study was to examine the association between baseline mtDNA-CN in middle-aged women (50-64 years) and incident VTE.

\section{Materials and methods}

\section{Study population}

The Women's Health In the Lund Area study (WHILA) is a prospective cohort study that was conducted in southern Sweden. Sample characteristics, data collection and clinical definitions for WHILA have been described previously $[29,30]$. Briefly, the study invited all women $(n=10,766)$ living in any of the five municipalities around the city of Lund by December 1995, and who were born between December 1935 and December 1945, to a screening procedure that took place from December 1995 until February 2000. A total of 6917 women consented to participate in the study, of which 6916 had complete datasets. Blood samples for DNA analyses were available at baseline only, and were collected midway through the study and therefore were available only for the last 3062 included women. Out of the 3062 blood sampled women, there were 541 samples with poor quality DNA as observed during droplet digital PCR analysis of reference gene. Thus, only 2521 women with sufficient quality of DNA were analyzed. These 541 women was excluded from analysis. Women $(n=13)$ treated with anticoagulants at baseline were also excluded (ATC code; B01AA03, B01AA01, and B01AB02). Women with prevalent VTE (defined below) or any of the following prevalent diagnoses at baseline were excluded: Stroke [ICD-7; 331, 332, 334.09. ICD-8; 430-434, 436. ICD-9; 430-434, 436. ICD-10; I60-I64 (not I63.6)]; Coronary heart disease (CHD) (ICD-7; 420. ICD-8; 410-414. ICD-9; 410-414. ICD-10; I20-I25.); and Cancer (ICD-7; 140-209). In the cohort, there were 22 women with prevalent stroke, 26 women with prevalent CHD, 232 women with prevalent cancer, and 120 women with VTE before baseline (self-reported and/or by register). Moreover, 14 women who were living in nursing homes were excluded. Some of the women had more than one reason for exclusion, which is why the numbers do not add up. After exclusions, a total of 2117 women remained of the 2521 women with sufficient quality DNA. After exclusions of prevalent stroke, prevalent CHD, prevalent cancer and prevalent VTE, 126 women remained with incident VTE. Of these, 39 women with VTE were censored in the cox regression due to incident CHD, stroke, or cancer before VTE during follow-up. Thus, after censoring for 39 incident cases of stroke, CHD, and cancer, we had 87 incident VTE cases in total.

The cohort was identified via the Swedish population registry that comprised all inhabitants in the Lund area. A health-screening program included laboratory examinations, blood samples and a basic baseline questionnaire that was mailed along with the invitation and collected in conjunction with the first examination. The baseline questionnaire included 104 questions concerning education, household, working status, perimenopausal status, medical history, drug treatment, personal and family history of diabetes or cardiovascular disease (myocardial infarction, stroke, deep venous thrombosis or hypertension in parents or siblings with an event before the age of 60 years). It also contained questions about habits like smoking, alcohol consumption, physical activity, general dietary habits, quality of life, as well as subjective physical and mental symptoms. This questionnaire was a composite of several validated questionnaires.

\section{Laboratory measurement of mtDNA-CN}

The mtDNA-CN was determined by droplet digital PCR (ddPCR) based method for quantification of absolute copy number of mtDNA in whole blood, as described in detail [31]. Compared to real-time PCR, ddPCR has greater precision and improved reproducibility and provides ultrasensitive and absolute nucleic acid quantification [32]. The used ddPCR method for mtDNA determination has been 
well-optimized with intra- and inter-assay coefficient variances as $3.1 \%$ and $4.2 \%$ respectively [31].

\section{Predictor variables}

Self-rated health (SRH) was assessed only at baseline from a single question, in which the participants were asked to rate their perceived health in a 7-graded Likert scale from "Very poor" to "Excellent, could not be better" ( 1 = very poor, $7=$ Excellent). In this study, alternative 1-4 was classified as poor SRH and 5-7 as good SRH. Weight and height were rounded off to the nearest $0.1 \mathrm{~kg}$ and $0.5 \mathrm{~cm}$. Body mass index (BMI) was calculated as weight in kilograms divided by height in meters squared $\left(\mathrm{kg} / \mathrm{m}^{2}\right)$. Varicose veins were defined by ICD-7; 460, ICD-8; 454, ICD-9; 454, and ICD10 ; I83. Women were categorized as current smokers (i.e., those who smoked regularly or occasionally), non-smokers and former smokers. Non-alcohol drinkers were defined as not drinking any alcohol (0 g/week), normal consumption more than 0-12 g/week, and high consumption as over $12 \mathrm{~g} /$ week. Low physical activity, i.e., less than 30 min vigorous activity 5 days a week [33] was defined by the three lowest answering alternatives (i.e., very low, low and light activity) (Table 1). Overall diet was defined by questions about intake of fat, sugar, fruit, or dietary fiber. If high intake of sugar or fat or low intake of dietary fiber or fruit were reported, the diet was classified as less healthy [29]. If low intake of sugar and fat and high intake of fruit and dietary fiber was reported, the diet was classified as healthy. Education was categorized into three groups: comprehensive school (9 years), upper secondary school (12 years), and university degree.

Information about diseases and medication was obtained from the Swedish Hospital Discharge Register, the Hospital Outpatient Register and the Swedish Cancer Register in addition to self-reported data from WHILA study baseline questionnaires and measurements.

\section{Outcome variable (VTE)}

The definition of VTE includes deep venous thrombosis (DVT), pulmonary embolism (PE), and other VTE types by the following ICD-codes from the Swedish Hospital Discharge Register and the Hospital Outpatient Register:

DVT (deep venous thromboembolism): ICD-7 463, 682. ICD-8 451, 671 (not 671.00). ICD-9 451 (not 451A) 671D 671E. ICD-10 I80 (not I80.0) O22.3, 0871. PE (pulmonary embolism): ICD-7 465, 684. ICD-8 451, 671 (not 671.00). ICD-9 415B, $416 \mathrm{~W}, 639 \mathrm{G}, 673 \mathrm{C}$. ICD-10 I26, O88.2, O082. Other VTE types: ICD-7 464, 466, 583.00, 334.40, 334.50. ICD-8 321, 452,453. ICD-9 437G, 451A, $452,453,671 \mathrm{C}, 671 \mathrm{~F}, 6171 \mathrm{X}$. ICD-10 I63.6, I676, I800, I81, I82, O222, O225, O229, O870, O873, O879, O087.
Table 1 Comparison between baseline characteristics between those with incident VTE and those without incident VTE

\begin{tabular}{|c|c|c|c|}
\hline Baseline measures & Incident VTE & No incident VTE & $\mathrm{P}$ \\
\hline $\mathrm{Age}^{*}$ & & & 0.34 \\
\hline Mean & 57.1 & 56.9 & \\
\hline Std dev & 2.8 & 2.8 & \\
\hline $\mathrm{n}$ & 126 & 1991 & \\
\hline mtDNA $^{*}$ & & & 0.49 \\
\hline Mean & 116.7 & 118.4 & \\
\hline Std dev & 28.9 & 27.0 & \\
\hline $\mathrm{n}$ & 126 & 1991 & \\
\hline $\mathrm{SBP}(\mathrm{mmHg})^{*}$ & & & 0.84 \\
\hline Mean & 132.3 & 132.0 & \\
\hline Std dev & 14.9 & 17.2 & \\
\hline $\mathrm{n}$ & 126 & 1990 & \\
\hline $\mathrm{DBP}(\mathrm{mmHg})^{*}$ & & & 0.46 \\
\hline Mean & 85.7 & 85.1 & \\
\hline Std dev & 8.5 & 9.0 & \\
\hline $\mathrm{n}$ & 126 & 1991 & \\
\hline Height mean ${ }^{*}(\mathrm{~cm})$ & 165.6 & 165.0 & 0.20 \\
\hline Std dev & 5.6 & 5.4 & \\
\hline $\mathrm{n}$ & 122 & 1948 & \\
\hline Weight* ${ }^{*}(\mathrm{~kg})$ & & & 0.01 \\
\hline Mean & 70.8 & 67.9 & \\
\hline Std dev & 11.4 & 10.9 & \\
\hline $\mathrm{n}$ & 114 & 1873 & \\
\hline Body mass index & & & 0.01 \\
\hline Mean* & 26.3 & 25.5 & \\
\hline Std dev & 4.0 & 4.0 & \\
\hline $\mathrm{n}$ & 126 & 1991 & \\
\hline Waist $(\mathrm{cm})^{*}$ & & & 0.01 \\
\hline Mean & 84.2 & 81.5 & \\
\hline Std dev & 10.1 & 10.3 & \\
\hline $\mathrm{N}$ & 125 & 1962 & \\
\hline Hip $(\mathrm{cm})^{*}$ & & & 0.02 \\
\hline Mean & 105.8 & 103.7 & \\
\hline Std dev & 7.5 & 8.0 & \\
\hline $\mathrm{N}$ & 125 & 1962 & \\
\hline Waist Hip Ratio & & & 0.11 \\
\hline Mean $^{*}$ & 0.79 & 0.78 & \\
\hline Std dev & 0.07 & 0.06 & \\
\hline $\mathrm{n}$ & 126 & 1989 & \\
\hline Smoker ${ }^{* *}$ & & & 0.40 \\
\hline No & $73(59.4 \%)$ & $1161(59.5 \%)$ & \\
\hline Current & $28(22.8 \%)$ & $366(18.7 \%)$ & \\
\hline Former & $22(17.9 \%)$ & $426(21.8 \%)$ & \\
\hline Alcohol $^{* *}$ & & & 0.54 \\
\hline $0 \mathrm{~g} / \mathrm{w}$ & $27(23.1 \%)$ & $468(24.8 \%)$ & \\
\hline$>0-12 \mathrm{~g} / \mathrm{w}$ & $77(65.8 \%)$ & $1154(61.1 \%)$ & \\
\hline$>12 \mathrm{~g} / \mathrm{w}$ & $13(11.1 \%)$ & $267(14.1 \%)$ & \\
\hline
\end{tabular}


Table 1 (continued)

\begin{tabular}{|c|c|c|c|}
\hline Baseline measures & Incident VTE & No incident VTE & $\mathrm{P}$ \\
\hline \multicolumn{3}{|l|}{ Education $^{* *}$} & 0.6 \\
\hline $7-9$ years & $35(28.0 \%)$ & $489(25.0 \%)$ & \\
\hline $10-12$ years & $51(40.8 \%)$ & $875(44.7 \%)$ & \\
\hline$>12$ years & $39(31.2 \%)$ & $595(30.4 \%)$ & \\
\hline \multicolumn{3}{|l|}{ Marital $^{* *}$} & 0.9 \\
\hline Married & $99(79.2 \%)$ & $1538(77.6 \%)$ & \\
\hline Unmarried & $6(4.8 \%)$ & $89(4.5 \%)$ & \\
\hline Divorced & $15(12.0 \%)$ & $244(12.3 \%)$ & \\
\hline Widowed & $5(4.0 \%)$ & $110(5.6 \%)$ & \\
\hline Low activity $^{* *}$ & $69(56.1 \%)$ & $1093(55.3 \%)$ & 0.9 \\
\hline High activity & $54(43.9 \%)$ & $850(43.7 \%)$ & \\
\hline \multicolumn{3}{|l|}{ Sugar $^{* * *}$} & 0.7 \\
\hline Daily & $8(6.5 \%)$ & $60(3.1 \%)$ & \\
\hline Sometimes & $78(62.9 \%)$ & $1326(67.3 \%)$ & \\
\hline Avoids & $38(30.7 \%)$ & $584(29.6 \%)$ & \\
\hline \multicolumn{3}{|l|}{ Fat in food ${ }^{* * *}$} & 0.2 \\
\hline Much & $8(6.7 \%)$ & $125(6.7 \%)$ & \\
\hline Careful with & $80(67.2 \%)$ & $1154(61.5 \%)$ & \\
\hline Avoids & $31(26.0 \%)$ & $597(31.8 \%)$ & \\
\hline \multicolumn{3}{|l|}{ Dietary fiber in food ${ }^{* * *}$} & 0.25 \\
\hline Low intake & $1(0.8 \%)$ & $21(1.1 \%)$ & \\
\hline Regularly & $79(64.8 \%)$ & $1164(59.5 \%)$ & \\
\hline High intake & $42(34.4 \%)$ & $773(39.5 \%)$ & \\
\hline \multicolumn{3}{|l|}{ Fruit $^{* * *}$} & 0.3 \\
\hline Much fruit & $83(66.4 \%)$ & $1229(62.2 \%)$ & \\
\hline Eats regularly & $39(31.2 \%)$ & $708(35.8 \%)$ & \\
\hline Eats rarely & $3(2.4 \%)$ & $39(21.97 \%)$ & \\
\hline \multicolumn{3}{|l|}{ Overall diet ${ }^{* * *}$} & 0.3 \\
\hline Less healthy & $16(12.8 \%)$ & $202(10.2 \%)$ & \\
\hline Healthy & $109(87.2 \%)$ & $1779(89.8 \%)$ & \\
\hline \multicolumn{3}{|l|}{ Self-rated health ${ }^{* * *}$} & 0.4 \\
\hline 1. Very poor & $1(0.8 \%)$ & $8(0.4 \%)$ & \\
\hline 2 & $0(0.0 \%)$ & $30(1.5 \%)$ & \\
\hline 3 & $5(4.0 \%)$ & $101(5.2 \%)$ & \\
\hline 4 & $19(15.3 \%)$ & $271(13.8 \%)$ & \\
\hline 5 & $37(28.8 \%)$ & $496(25.3 \%)$ & \\
\hline 6 & $38(30.7 \%)$ & $5589(30.1 \%)$ & \\
\hline 7. Excellent & $24(19.4 \%)$ & $463(23.7 \%)$ & \\
\hline \multicolumn{3}{|l|}{ Self-rated health group ${ }^{* * *}$} & 0.8 \\
\hline Poor & $25(20.2 \%)$ & $410(20.1 \%)$ & \\
\hline Good & $99(79.8 \%)$ & $1548(79.1 \%)$ & \\
\hline \multicolumn{3}{|l|}{ Amount of food ${ }^{* * *}$} & 0.60 \\
\hline Big portions & $5(4.4 \%)$ & $129(7.0 \%)$ & \\
\hline Regularly & $81(71.7 \%)$ & $1186(64.5 \%)$ & \\
\hline Small portions & $27(23.9 \%)$ & $525(28.5 \%)$ & \\
\hline \multicolumn{3}{|l|}{ Diabetes before baseline ${ }^{* * *}$} & 0.5 \\
\hline Yes & $1(0.8 \%)$ & $27(1.4 \%)$ & \\
\hline No & $124(99.2 \%)$ & $1941(98.6 \%)$ & \\
\hline
\end{tabular}

Table 1 (continued)

\begin{tabular}{lcll}
\hline Baseline measures & Incident VTE & No incident VTE & P \\
\hline Hypertension $^{* *}$ & & & 0.75 \\
Yes & $23(18.4 \%)$ & $343(17.3 \%)$ & \\
No & $102(81.6 \%)$ & $1639(82 \%)$ & \\
Varicose veins & \\
Yes & & & 0.15 \\
No & $5(4.0 \%)$ & $41(2.1 \%)$ & \\
Acetylsalicylic treatment & \\
Yes & $121(96.0 \%)$ & $1950(98.0 \%)$ & \\
No & $1(0.8 \%)$ & $16(0.8 \%)$ & 0.99 \\
Knowledge about family history & & \\
Yes & $16(12.9 \%)$ & $180(9.3 \%)$ & \\
No & $96(77.4 \%)$ & $1622(83.4 \%)$ & \\
Do not know & $12(9.7 \%)$ & $144(7.4 \%)$ & \\
\hline
\end{tabular}

Exclusions: Poor quality mtDNA-CN, prevalent VTE, prevalent $\mathrm{CHD}$, prevalent stroke, prevalent cancer, those medicated with anticoagulant, and those living in nursing homes

P-values were calculated with two-sided Student's t-test ${ }^{*}$ for continuous variables, with Chi2-test** for normal distributed categorical variables, and with Wilcoxon rank sum test*** for not normally distributed categorical variables between incident VTE and no incident VTE

Bold numbers indicate $\mathrm{P}$ values $<0.05$

Physical activity was dichotomized into Low activity (Non, Mostly sitting, and Light activity) and High activity (1-2 h/week, regularly and Very high). Self-rated health was dichotomized into the variable Poor self-rated health, with group 1-4 as poor self-rated health and 5-7 as good self-rated health

\section{Statistical analysis}

Levels of mtDNA-CN were used as a dichotomized variable according to median, though mtDNA-CN was also used as a continuous variable in the analysis. In the multivariate models, waist circumference was used instead of BMI; this was due to previous studies showing waist circumference as a valid predictor for VTE [34]. A power analysis revealed that a risk ratio of 1.8 could be detected at a significance level of 5\% (two-sided) with a power of $82 \%$ in the studied population when using mtDNA-CN as a dichotomous predictor variable (https://www.openepi.com/Power/PowerCohort. $\mathrm{htm})$. P-values were calculated with two-sided Student's t test for continuous variables, with $\chi^{2}$-test for dichotomized and normal distributed categorical variables, and Wilcoxon rank sum test for not normally distributed categorical variables. Cox proportional hazards regression was used to analyze the relationship between different variables and time to VTE. Hazard ratios (HR) with $95 \%$ confidence intervals (CI) were calculated. Women who were affected by stroke, CHD, or cancer diagnosis before the VTE during the follow-up time were censored. Well-known risk factors for increased 
VTE-risk were used as confounding variables in the multivariate analysis. At first, in the multivariable model, there was an adjustment for mtDNA-CN and age. In the second model, smoking, waist circumference, physical activity, and varicose veins were added. Among the categorical variables, the same category was used as reference through all analysis. Regarding smoking, "non-smoker" was used as reference, in physical activity the reference was "low physical activity", in varicose veins it was "no varicose veins" reference, and in mtDNA-CN median, under the median $(<117)$ was reference. The mtDNA-CN median and mtDNA-CN as a continuous variable were analyzed separately in the different models by Cox regression using the same adjustments. In the main analysis, we excluded all the patients with prevalent VTE, CHD, stroke, cancer, and women treated with anticoagulants at baseline or living in nursing homes. During follow-up, those with incident CHD, stroke, or cancer before VTE were censored. At the next step, a sensitivity analysis was conducted; the only exclusions in the sensitivity analysis were those with poor quality DNA. All other excluded and censored individuals were included in the sensitivity analysis. P-values $<0.05$ were considered significant. Analyses were performed in STATA 16.1.

\section{Result}

Measurements at baseline were compared between women, with and without incident VTE, during follow-up (Table 1). Women with incident VTE had a significantly higher weight $(\mathrm{p}=0.01)$ and BMI $(\mathrm{p}=0.01)$ at baseline, and a significantly greater circumference regarding both waist $(p=0.01)$ and hip $(\mathrm{p}=0.02)$. There was a greater proportion, among those with incident VTE, who had varicose veins.

\section{Incident VTE and mtDNA-CN}

During the follow-up time of 17.9 years, 87 women were diagnosed with VTE. The sum of follow-up time was $31,073.123$ years corresponding to a VTE incident rate at 2.8 (95\% CI 2.3-3.4) per 1000 person-years. Unadjusted Coxregression analysis was conducted (Table 2) to determine any associations between possible risk factors and incident VTE. The univariate Cox-regression showed no significant association between increased mtDNA-CN and lower risk for VTE $(\mathrm{HR}=0.99,95 \%$ CI $0.98-1.00, \mathrm{p}=0.13)$. There was a nonsignificant decreased risk of VTE with mtDNA-CN over the median $(\mathrm{HR}=0.76,95 \%$ CI 0.50-1.17, $\mathrm{p}=0.21)$ compared with mtDNA-CN under median. Among potential VTE risk factors, statistically significant associations were observed with weight $(\mathrm{HR}=1.02,95 \%$ CI $1.00-1.04 \mathrm{p}=0.01)$, waist circumference $(\mathrm{HR}=1.02,95 \%$ CI 1.00-1.04, $\mathrm{p}=0.01)$, hip circumference $(\mathrm{HR}=1.0395 \%$ CI $1.00-1.06 \mathrm{p}=0.02)$, and varicose veins $(\mathrm{HR}=2.89,95 \% \mathrm{CI} 1.17-7.13, \mathrm{p}=0.02) . \mathrm{A}$ significant association with sugar intake was observed. No significant association was shown with incident VTE and current smokers $(H R=1.30,95 \%$ CI $0.78-2.18, p=0.32)$ or former smokers $(\mathrm{HR}=0.74,95 \%$ CI $0.41-1.33 \mathrm{p}=0.31)$. Regarding physical activity $(\mathrm{HR}=0.87,95 \%$ CI $0.56-1.34$ $\mathrm{p}=0.52$ ), there were no significant associations with incident VTE. Likewise, there was not shown any significant associations between incident VTE and self-rated health $(\mathrm{HR}=1.74,95 \%$ CI 0.24-12.49 $\mathrm{p}=0.58$ ) (Table 2).

In the second step, a multivariable Cox regression analysis was performed, at first when adjusted for age (Table 3) dichotomized mtDNA-CN over median showed a non-significant decreased risk for VTE $(\mathrm{HR}=0.76,95 \%$ CI $0.50-1.77$ $\mathrm{p}=0.22$ ) compared to mtDNA-CN under the median (Table 3). With age adjusted Cox regression and mtDNA$\mathrm{CN}$ as a continuous variable, a non-significant decreased risk was shown with increasing mtDNA-CN $(\mathrm{HR}=0.99$, 95\% CI 0.98-1.00 p=0.14). The last model 3, adjusted for age, smoking, waist circumference, physical activity, and varicose veins showed mtDNA-CN over the median a nonsignificant decreased risk of incident VTE $(\mathrm{HR}=0.89,95 \%$ CI $0.57-1.38 \mathrm{p}=0.60)$ using mtDNA-CN under the median as reference. Using the same adjustments but with mtDNA$\mathrm{CN}$ as a continuous variable showed no effect of neither decreased nor increased risk for incident VTE $(\mathrm{HR}=1.00$, 95\% CI 0.99-1.00 p=0.34) (Table 3).

\section{Sensitivity analysis}

The only exclusions done in the sensitivity analysis were those with poor quality DNA (541 women). In the sensitivity analyses, a total of 2521 women were remaining and out of these, 142 women were affected with incident VTE during follow-up. Moreover, in the sensitivity analyses, no censoring was performed for women with incident stroke, CHD, or cancer. The sum of follow-up time in the sensitivity analysis was 38,805.318 years corresponding to a VTE incident rate at 3.7 (95\% CI 3.1-4.3) per 1000 person-years total analysis time at risk under observation. The result of the univariate sensitivity analysis (Supplementary Table 1) is approximately the same as the univariate main analysis regarding hazard ratios and confidence intervals. The same variables showing significant association in main analysis were significant in the sensitivity analysis, except for knowledge of family history of VTE, which showed an association with incident VTE in the sensitivity analysis $(\mathrm{HR}=1.67,95 \% \mathrm{CI}$ 1.05-2.68, $\mathrm{p}=0.03$ ) (Supplementary Table 1). Regarding varicose veins, it was the opposite with no significant associations in the sensitivity analysis (Supplementary Table 1). The multivariable sensitive analysis (Table 4) showed the same pattern as the main multivariable analysis. There were 
Table 2 Univariate Cox regression with variables associated with VTE

\begin{tabular}{|c|c|c|c|c|c|}
\hline & Hazard ratio & $95 \% \mathrm{CI}$ & $\mathrm{p}$ & $\mathrm{n}$ & Failures \\
\hline mtDNA-CN & 0.99 & $0.99-1.00$ & 0.013 & 2117 & 87 \\
\hline mtDNA-CN median ${ }^{*}$ & 0.76 & $0.50-1.17$ & 0.21 & 2117 & 87 \\
\hline Age & 1.05 & $0.97-1.13$ & 0.23 & 2117 & 87 \\
\hline Height & 1.02 & $0.99-1.06$ & 0.20 & 2070 & 85 \\
\hline Weight & 1.02 & $1.00-1.04$ & 0.01 & 1987 & 79 \\
\hline BMI & 1.18 & $0.93-1.49$ & 0.18 & 2117 & 87 \\
\hline Waist circumference & 1.02 & $1.00-1.04$ & 0.01 & 2087 & 86 \\
\hline Hip circumference & 1.03 & $1.00-1.05$ & 0.02 & 2087 & 86 \\
\hline WHR & 1.29 & $0.51-3.15$ & 0.59 & 2115 & 87 \\
\hline Diastolic blood pressure & 1.01 & $0.99-1.04$ & 0.30 & 2117 & 87 \\
\hline Systolic blood pressure & 1.00 & $0.99-1.02$ & 0.62 & 2116 & 87 \\
\hline Education & & & & 2084 & 87 \\
\hline $7-9$ years & 1.39 & $0.84-2.28$ & 0.20 & & \\
\hline $10-12$ years & Ref & & & & \\
\hline$>12$ years & 1.00 & $0.60-1.67$ & 1.00 & & \\
\hline Marital & & & & 2106 & 87 \\
\hline Married & Ref & & & & \\
\hline Unmarried & 1.32 & $0.53-3.29$ & 0.54 & & \\
\hline Divorced & 1.07 & $0.57-2.03$ & 0.83 & & \\
\hline Widowed & 0.89 & $0.32-2.44$ & 0.82 & & \\
\hline High activity /low activity & 0.87 & $0.56-1.34$ & 0.52 & 2066 & 85 \\
\hline Smoking & & & & 2076 & 85 \\
\hline Non smoker & Ref & & & & \\
\hline Current smoker & 1.30 & $0.78-2.18$ & 0.32 & & \\
\hline Former smoker & 0.74 & $0.41-1.33$ & 0.31 & & \\
\hline Alcohol & & & & 2006 & 81 \\
\hline $0 \mathrm{~g} / \mathrm{w}$ & 0.98 & $0.59-1.64$ & 0.94 & & \\
\hline $0-12 \mathrm{~g} / \mathrm{w}$ & Ref & & & & \\
\hline$>12 \mathrm{~g} / \mathrm{w}<130 \mathrm{~g} / \mathrm{w}$ & 0.67 & $0.32-1.40$ & 0.28 & & \\
\hline Sugar & & & & 2094 & 87 \\
\hline Daily & 2.87 & $1.30-6.33$ & $<0.01$ & & \\
\hline Sometimes & Ref & & & & \\
\hline Avoids & 1.32 & $0.84-2.08$ & 0.23 & & \\
\hline Fat in food & & & & 1995 & 81 \\
\hline Much & 1.08 & $0.47-2.52$ & 0.85 & & \\
\hline Careful with & Ref & & & & \\
\hline Avoids & 0.84 & $0.51-1.38$ & 0.49 & & \\
\hline Fiber & & & & 2080 & 84 \\
\hline Low intake & 1.23 & $0.17-8.88$ & 0.84 & & \\
\hline Regularly & Ref & & & & \\
\hline Much & 0.96 & $0.62-1.49$ & 0.85 & & \\
\hline Fruit & & & & 2101 & 87 \\
\hline Much fruit & 0.96 & $0.61-1.48$ & 0.84 & & \\
\hline Eats regularly & Ref & & & & \\
\hline Eats rarely & 1.16 & $0.28-4.84$ & 0.84 & & \\
\hline $\begin{array}{l}\text { Overall diet } \\
\text { Less healthy/healthy }\end{array}$ & 1.56 & $861-2.98$ & 0.14 & 2106 & 87 \\
\hline Amount of food & & & & 1953 & 77 \\
\hline Big portions & 0.64 & $0.23-1.77$ & 0.39 & & \\
\hline Regularly & Ref & & & & \\
\hline Small portions & 0.64 & $0.37-1.12$ & 0.12 & & \\
\hline
\end{tabular}


Table 2 (continued)

\begin{tabular}{llllll}
\hline & Hazard ratio & $95 \%$ CI & $\mathrm{p}$ & $\mathrm{n}$ & Failures \\
\hline Acetylsalicylic & 1.83 & $0.25-13.13$ & 0.55 & 2117 & 87 \\
Knowledge about FH** VTE & & & & 2070 & 86 \\
$\quad$ Yes & 1.58 & $0.86-2.92$ & 0.14 & & \\
No & Ref & & & & \\
Do not know & 1.17 & $0.54-2.55$ & 0.69 & & \\
Diabetes & 0.89 & $0.12-6.39$ & 0.91 & 2093 & 87 \\
Hypertension & 1.30 & $0.78-2.19$ & 0.32 & 2107 & 87 \\
Prevalent varicose veins & 2.89 & $1.17-7.13$ & $\mathbf{0 . 0 2}$ & 2117 & 87 \\
Self-rated health & 1.74 & $0.24-12.49$ & 0.58 & 2117 & 87 \\
Poor/good & & & & & \\
\hline
\end{tabular}

Exclusions: Poor quality mtDNA-CN, prevalent VTE, prevalent CHD, prevalent stroke, prevalent cancer, those medicated with anticoagulant, and those living in nursing homes. Censored for CVD stroke and cancer before VTE diagnosis during follow-up. Self-rated health was dichotomized into the variable Poor selfrated health, with group 1-4 as poor self-rated health and 5-7 as good self-rated health. Bold numbers indicate statistically significant differences

*Reference under median

** $=$ family history

Table 3 Cox regression with mtDNA-CN, analyses with median and continuous were done in separate models

\begin{tabular}{llll}
\hline Model & 1 & 2 & 3 \\
\hline Total n & 2117 & 2117 & 2003 \\
Failures n & 87 & 87 & 82 \\
mtDNA median & & \\
HR & 0.76 & 0.76 & 0.89 \\
CI & $0.49-1.17$ & $0.50-1.17$ & $0.57-1.38$ \\
P & 0.21 & 0.22 & 0.60 \\
mtDNA (continuous) & & \\
HR & 0.99 & 0.99 & 1.00 \\
CI & $0.98-1.00$ & $0.98-1.00$ & $0.99-1.00$ \\
p & 0.13 & 0.14 & 0.34 \\
& Model 1 mtDNA-CN & Model 2 & Model 3 mtDNA-CN, age, smoking, waist circum- \\
& & mtDNA-CN & ference physical activity and prevalent varicose \\
& & and age & veins \\
\hline
\end{tabular}

Exclusions: Poor quality mtDNA-CN, prevalent VTE, prevalent CHD, prevalent stroke, prevalent cancer, those medicated with anticoagulant, and those living in nursing homes. Censored for CVD stroke and cancer before VTE diagnosis during follow-up

* Reference is mtDNA-CN under the median minor differences in hazard ratios and level of significance between the main analysis and the sensitivity analysis.

\section{Discussion}

The present first study on mtDNA-CN and future VTE risk found no significant association between mtDNA-CN and incident VTE. Based on our results, we suggest that mtDNA-CN should not be considered a biomarker that plays a major role for developing VTE. VTE and arterial CVD share many risk factors, but some are unique to VTE or CVD [3]. The mtDNA-CN appears to be a factor that is only associated with CVD [15] and not VTE. Thus, mitochondrial dysfunction reflected by low copy number of mtDNA appears not to be of similar importance in VTE as in arterial CVD [15]. Due to limited study size, we may not exclude minor associations. The level of mtDNA-CN is determined by heredity, in addition to the influence on one's lifestyle habits such as physical activity, smoking, and alcohol consumption [21-25, 35]. Poor self-rated health is also associated with low levels of mtDNA-CN [19]. Factors like these, for instance smoking and physical activity, are important for the development of arterial CVD [26]. Nevertheless, we found no significant association between VTE and mtDNA-CN. 
Table 4 Sensitivity analysis cox regression with mtDNA-CN, analyses with median and continuous were done in separate models

\begin{tabular}{llll}
\hline Model & 1 & 2 & 3 \\
\hline Total n & 2401 & 2401 & 2277 \\
Failures n & 142 & 142 & 136 \\
mtDNA median* & & \\
HR & 0.87 & 0.87 & 0.94 \\
CI & $0.63-1.21$ & $0.63-1.22$ & $0.67-1.31$ \\
$\mathrm{p}$ & 0.41 & 0.42 & 0.74 \\
mtDNA (continuous) & & \\
HR & 1.00 & 1.00 & 1.00 \\
CI & $0.99-1.00$ & $0.99-1.00$ & $0.99-1.01$ \\
$\mathrm{p}$ & 0.40 & 0.41 & 0.66 \\
& Model 1 mtDNA-CN & Model 2 & Model 3 mtDNA-CN, age, smoking, waist circum- \\
& & mtDNA-CN & ference physical activity and prevalent varicose \\
& & and age & veins \\
\hline
\end{tabular}

The only exclusions were those with poor quality mtDNA-CN

*Reference is mtDNA-CN under the median
An association between incident VTE and dietary habits has previously been reported [36] where a diet with low amount of red meat and high amount of grains and vegetables lowers the risk of incident VTE. Although, in our study, only self-reported daily consumption of sugar showed a significantly increased risk of VTE in this cohort. High sugar intake is a well-known dietary habit that increases the risk of arterial CVD and might also affect VTE risk [37, 38]. However, we think the association with sugar consumption and VTE in the present study is a chance finding. A previous study of the same cohort containing all 6917 women did not show any significant associations between daily sugar consumption, other dietary habits or any significant association between physical activity and incident VTE [30]. In fact, diet remains to be a proven risk factor for VTE [39].

A limitation of the study is the study size. However, wellestablished risk factors such as anthropometric measures for overweight (weight, BMI, waist circumference, and waist circumference) and varicose veins were all associated with future VTE risk. Even if increasing age is a well-known risk factor for VTE [40, 41], no association between increasing age and incident VTE was found, most likely due to the narrow age span between 50 and 60 years of age at baseline. The method used for measuring physical activity in this study can affect the results, related to the known risk of overestimating the time in physical activity when self-reported [42, 43], which is another limitation of the study regarding physical activity. Another limitation is the inclusion of women only. However, there is no hypothesis suggesting that the importance of mtDNA-CN should be sex dependent. Still, the copy number of mitochondrial DNA has been reported to be lower in males compared with females both in humans [44, 45] and in Drosophila melanogaster [45, 46]. It will therefore be of interest to investigate whether mtDNA$\mathrm{CN}$ is associated with VTE among males.

A strength of the study is the population-based cohort design with long follow-up time. Using a hospital-based diagnosis of VTE is another strength. The Swedish Hospital register has a general validity between 85 and $95 \%$ [46]. VTE has been validated with a $95 \%$ positive predictive value [47]. In Sweden, VTE is usually confirmed with objective methods [48-50].

Several common risk factors [3-5] for both VTE and CVDs have been described, and mtDNA-CN has been shown to be a risk indicator of CVDs [15]. Although, mtDNA-CN does not to appear to be a biomarker that is associated with VTE.

\section{Conclusion}

MtDNA-CN was not associated with incident VTE among middle-aged women. MtDNA-CN is suggested not to be of major importance for the development of VTE.

\section{Strengths and limitations}

This is the first study aiming to investigate the association between mtDNA-CN and incident VTE, which is a strength of this study. Performing the study in a small cohort containing only middle-aged women with a narrow age span is a limitation.

Supplementary Information The online version contains supplementary material available at https://doi.org/10.1007/s11239-021-02446-y. 
Acknowledgements The authors wish to thank the Center for Primary Healthcare Research (CPF) statistician, Karolina Palmér, for the statistical guidance and data management, and science editor, Patrick Reilly, for his useful comments on the text.

Author contributions PN: Collaborating with study design, statistical analysis, writing paper. AM: experimental study design and analysis of mtDNA-CN, writing and editing paper. JS: Writing and editing the paper. KS: Writing and editing the paper. BZ: Study design, writing, editing paper, and funding.

Funding Open access funding provided by Lund University. This work was supported by grants awarded to Dr Bengt Zöller by ALF funding from Region Skåne. The funders had no role in the study design; in the collection, analysis, and interpretation of data; in the writing of the report; and in the decision to submit the article for publication.

\section{Declarations}

Conflict of interest The authors declare that they have no competing interests.

Ethical approval The regional ethical committee at Lund University approved the study (approval nos. 2011/494 and 2015/6) and written informed consent was given by all the participants in the study after full explanation of the purpose and all the protocols were conducted in accordance with the Helsinki Declaration and the Data Registry Inspection in Stockholm. Informed consent was obtained from all participants

Open Access This article is licensed under a Creative Commons Attribution 4.0 International License, which permits use, sharing, adaptation, distribution and reproduction in any medium or format, as long as you give appropriate credit to the original author(s) and the source, provide a link to the Creative Commons licence, and indicate if changes were made. The images or other third party material in this article are included in the article's Creative Commons licence, unless indicated otherwise in a credit line to the material. If material is not included in the article's Creative Commons licence and your intended use is not permitted by statutory regulation or exceeds the permitted use, you will need to obtain permission directly from the copyright holder. To view a copy of this licence, visit http://creativecommons.org/licenses/by/4.0/.

\section{References}

1. Heit JA, Silverstein MD, Mohr DN, Petterson TM, Lohse CM, O'Fallon WM et al (2001) The epidemiology of venous thromboembolism in the community. Thromb Haemost 86(1):452-463

2. Flinterman LE, van Hylckama VA, Cannegieter SC, Rosendaal FR (2012) Long-term survival in a large cohort of patients with venous thrombosis: incidence and predictors. PLoS Med 9(1):e1001155. https://doi.org/10.1371/journal.pmed.1001155

3. Lowe GD (2008) Common risk factors for both arterial and venous thrombosis. Br J Haematol 140(5):488-495. https://doi. org/10.1111/j.1365-2141.2007.06973.x

4. Lippi G, Mattiuzzi C, Franchini M (2015) Sleep apnea and venous thromboembolism. A systematic review. Thromb Haemost 114(5):958-963. https://doi.org/10.1160/TH15-03-0188

5. Deflandre E, Degey S, Opsomer N, Brichant JF, Joris J (2016) Obstructive sleep apnea and smoking as a risk factor for venous thromboembolism events: review of the literature on the common pathophysiological mechanisms. Obes Surg 26(3):640-648. https://doi.org/10.1007/s11695-015-2012-0

6. Somers VK, White DP, Amin R, Abraham WT, Costa F, Culebras A et al (2008) Sleep apnea and cardiovascular disease: an American Heart Association/American College Of Cardiology Foundation Scientific Statement from the American Heart Association Council for High Blood Pressure Research Professional Education Committee, Council on Clinical Cardiology, Stroke Council, and Council On Cardiovascular Nursing. In collaboration with the National Heart, Lung, and Blood Institute National Center on Sleep Disorders Research (National Institutes of Health). Circulation 118(10):1080-1111. https://doi.org/10.1161/CIRCULATIO NAHA.107.189375

7. Franchini M, Mannucci PM (2008) Venous and arterial thrombosis: different sides of the same coin? Eur J Intern Med 19(7):476481. https://doi.org/10.1016/j.ejim.2007.10.019

8. Prandoni $\mathrm{P}$ (2017) Venous and arterial thrombosis: is there a link? Adv Exp Med Biol 906:273-283. https://doi.org/10.1007/5584_ 2016_121

9. Grundy SM, Brewer HB Jr, Cleeman JI, Smith SC Jr, Lenfant C, American Heart A et al (2004) Definition of metabolic syndrome: report of the National Heart, Lung, and Blood Institute/American Heart Association conference on scientific issues related to definition. Circulation 109(3):433-438. https://doi.org/10.1161/01.CIR. 0000111245.75752.C6

10. Ahti TM, Makivaara LA, Luukkaala T, Hakama M, Laurikka JO (2010) Lifestyle factors and varicose veins: does cross-sectional design result in underestimate of the risk? Phlebology 25(4):201206. https://doi.org/10.1258/phleb.2009.009031

11. Tiwari A, Lester W, Tang TY (2018) Varicose veins and deep venous thrombosis. JAMA 320(5):509-510. https://doi.org/10. 1001/jama.2018.7319

12. Chang SL, Chen PC (2018) Varicose veins and deep venous thrombosis-reply. JAMA 320(5):510. https://doi.org/10.1001/ jama.2018.7331

13. Zoller B, Ji J, Sundquist J, Sundquist K (2014) Venous thromboembolism and varicose veins share familial susceptibility: a nationwide family study in Sweden. J Am Heart Assoc. https:// doi.org/10.1161/JAHA.114.000850

14. Wilson PWF, D'Agostino RB, Parise H, Sullivan L, Meigs JB (2005) Metabolic syndrome as a precursor of cardiovascular disease and type 2 diabetes mellitus. Circulation 112(20):3066-3072. https://doi.org/10.1161/CIRCULATIONAHA.105.539528

15. Yue P, Jing S, Liu L, Ma F, Zhang Y, Wang C et al (2018) Association between mitochondrial DNA copy number and cardiovascular disease: current evidence based on a systematic review and meta-analysis. PLoS ONE 13(11):e0206003. https://doi.org/10. 1371/journal.pone. 0206003

16. Huang CH, Su SL, Hsieh MC, Cheng WL, Chang CC, Wu HL et al (2011) Depleted leukocyte mitochondrial DNA copy number in metabolic syndrome. J Atheroscler Thromb 18(10):867-873. https://doi.org/10.5551/jat.8698

17. Lee J-Y, Lee D-C, Im J-A, Lee J-W (2014) Mitochondrial DNA copy number in peripheral blood is independently associated with visceral fat accumulation in healthy young adults. Int $\mathrm{J}$ Endocrinol 2014:586017. https://doi.org/10.1155/2014/586017

18. Maximov VN, Malyutina SK, Orlov PS, Ivanoschuk DE, Mikhailova SV, Shapkina MY et al (2019) Mitochondrial DNA copy number of leucocytes as ageing marker and risk factors for age-related diseases in human. Adv Gerontol 32(3):422-430

19. Takahashi PY, Jenkins GD, Welkie BP, McDonnell SK, Evans JM, Cerhan JR et al (2018) Association of mitochondrial DNA copy number with self-rated health status. Appl Clin Genet 11:121127. https://doi.org/10.2147/TACG.S167640

20. van der Linde RM, Mavaddat N, Luben R, Brayne C, Simmons RK, Khaw KT et al (2013) Self-rated health and cardiovascular 
disease incidence: results from a longitudinal population-based cohort in Norfolk, UK. PLoS ONE 8(6):e65290. https://doi.org/ 10.1371/journal.pone.0065290

21. Vyas CM, Ogata S, Reynolds CF, Mischoulon D, Chang G, Cook NR et al (2020) Lifestyle and behavioral factors and mitochondrial DNA copy number in a diverse cohort of mid-life and older adults. PLoS ONE 15(8):e0237235. https://doi.org/10.1371/journal.pone. 0237235

22. von Wurmb-Schwark N, Ringleb A, Schwark T, Broese T, Weirich S, Schlaefke D et al (2008) The effect of chronic alcohol consumption on mitochondrial DNA mutagenesis in human blood. Mutat Res 637(1-2):73-79. https://doi.org/10.1016/j.mrfmmm.2007.07.003

23. Cakir Y, Yang Z, Knight CA, Pompilius M, Westbrook D, Bailey SM et al (2007) Effect of alcohol and tobacco smoke on mtDNA damage and atherogenesis. Free Radic Biol Med 43(9):1279_ 1288. https://doi.org/10.1016/j.freeradbiomed.2007.07.015

24. Chang YK, Kim DE, Cho SH, Kim JH (2016) Association between leukocyte mitochondrial DNA copy number and regular exercise in postmenopausal women. Korean J Fam Med 37(6):334-339. https://doi.org/10.4082/kjfm.2016.37.6.334

25. Eluamai A, Brooks K (2013) Effect of aerobic exercise on mitochondrial DNA and aging. J Exerc Sci Fit 11(1):1-5. https://doi. org/10.1016/j.jesf.2013.03.003

26. Yusuf S, Hawken S, Ounpuu S, Dans T, Avezum A, Lanas F et al (2004) Effect of potentially modifiable risk factors associated with myocardial infarction in 52 countries (the INTERHEART study): case-control study. Lancet 364(9438):937-952. https://doi.org/10. 1016/S0140-6736(04)17018-9

27. Johansson M, Johansson L, Wennberg P, Lind M (2019) Physical activity and risk of first-time venous thromboembolism. Eur J Prev Cardiol 26(11):1181-1187. https://doi.org/10.1177/20474 87319829310

28. Kunutsor SK, Makikallio TH, Seidu S, de Araujo CGS, Dey RS, Blom AW et al (2020) Physical activity and risk of venous thromboembolism: systematic review and meta-analysis of prospective cohort studies. Eur J Epidemiol 35(5):431-442. https://doi.org/ 10.1007/s10654-019-00579-2

29. Samsioe G, Lidfeldt J, Nerbrand C, Nilsson P (2010) The women's health in the Lund area (WHILA) study-an overview. Maturitas 65(1):37-45. https://doi.org/10.1016/j.maturitas.2009.11.009

30. Nymberg P, Stenman E, Calling S, Sundquist J, Sundquist K, Zoller B (2020) Self-rated health and venous thromboembolism among middle-aged women: a population-based cohort study. $\mathrm{J}$ Thromb Thrombolysis 49(3):344-351. https://doi.org/10.1007/ s11239-019-01995-7

31. Memon AA, Zoller B, Hedelius A, Wang X, Stenman E, Sundquist J et al (2017) Quantification of mitochondrial DNA copy number in suspected cancer patients by a well optimized ddPCR method. Biomol Detect Quantif 13:32-39. https://doi.org/10.1016/j.bdq. 2017.08.001

32. Hindson CM, Chevillet JR, Briggs HA, Gallichotte EN, Ruf IK, Hindson BJ et al (2013) Absolute quantification by droplet digital PCR versus analog real-time PCR. Nat Methods 10(10):10031005. https://doi.org/10.1038/nmeth.2633

33. WH Organization (2011) Global recommendations on physical activity for health. World Health Organization, Geneva

34. Borch KH, Braekkan SK, Mathiesen EB, Njolstad I, Wilsgaard T, Stormer J et al (2010) Anthropometric measures of obesity and risk of venous thromboembolism: the tromso study. Arterioscler Thromb Vasc Biol 30(1):121-127. https://doi.org/10.1161/ ATVBAHA.109.188920

35. Xing J, Chen M, Wood CG, Lin J, Spitz MR, Ma J et al (2008) Mitochondrial DNA content: its genetic heritability and association with renal cell carcinoma. J Natl Cancer Inst 100(15):11041112. https://doi.org/10.1093/jnci/djn213
36. Steffen LM, Folsom AR, Cushman M, Jacobs DR Jr, Rosamond WD (2007) Greater fish, fruit, and vegetable intakes are related to lower incidence of venous thromboembolism: the longitudinal investigation of thromboembolism etiology. Circulation 115(2):188-195. https://doi.org/10.1161/CIRCULATIONAHA.106.641688

37. Mirtschink P, Jang C, Arany Z, Krek W (2018) Fructose metabolism, cardiometabolic risk, and the epidemic of coronary artery disease. Eur Heart J 39(26):2497-2505. https://doi.org/10.1093/ eurheartj/ehx518

38. The LH (2018) Sugar, video games, and VTE: an unseen connection? Lancet Haematol 5(5):e181. https://doi.org/10.1016/s23523026(18)30052-8

39. Hansen-Krone IJ, Enga KF, Njølstad I, Hansen JB, Braekkan SK (2012) Heart healthy diet and risk of myocardial infarction and venous thromboembolism. The tromso study. Thromb Haemost 108(3):554-560

40. Bizien N, Noel-Savina E, Tromeur C, Delluc A, Mottier D, Leroyer $C$ et al (2011) Age is a major risk factor of venous thromboembolism (VTE). Eur Respir J 38(Suppl 55):p3936

41. Anderson FA Jr, Spencer FA (2003) Risk factors for venous thromboembolism. Circulation 107(23 Suppl 1):I9-16. https:// doi.org/10.1161/01.CIR.0000078469.07362.E6

42. Troiano RP, Berrigan D, Dodd KW, Masse LC, Tilert T, McDowell M (2008) Physical activity in the United States measured by accelerometer. Med Sci Sports Exerc 40(1):181-188. https://doi. org/10.1249/mss.0b013e31815a51b3

43. Forsen L, Loland NW, Vuillemin A, Chinapaw MJ, van Poppel MN, Mokkink LB et al (2010) Self-administered physical activity questionnaires for the elderly: a systematic review of measurement properties. Sports Med 40(7):601-623. https://doi.org/10.2165/ 11531350-000000000-00000

44. Skuratovskaia D, Litvinova L, Vulf M, Zatolokin P, Popadin K, Mazunin I (2019) From normal to obesity and back: the associations between mitochondrial dna copy number, gender, and body mass index. Cells. https://doi.org/10.3390/cells8050430

45. Mengel-From J, Svane AM, Pertoldi C, Nygaard Kristensen T, Loeschcke V, Skytthe A et al (2019) Advanced parental age at conception and sex affects mitochondrial DNA copy number in human and fruit flies. J Gerontol A Biol Sci Med Sci 74(12):18531860. https://doi.org/10.1093/gerona/glz070

46. Kristensen TN, Loeschcke V, Tan Q, Pertoldi C, Mengel-From J (2019) Sex and age specific reduction in stress resistance and mitochondrial DNA copy number in Drosophila melanogaster. Sci Rep 9(1):12305. https://doi.org/10.1038/s41598-019-48752-7

47. Ludvigsson JF, Andersson E, Ekbom A, Feychting M, Kim JL, Reuterwall C, Heurgren M, Olausson PO (2011) External review and validation of the Swedish national inpatient register. BMC Public Health 11:450. https://doi.org/10.1186/1471-2458-11-450

48. Rosengren A, Fredén M, Hansson PO, Wilhelmsen L, Wedel H, Eriksson H (2008) Psychosocial factors and venous thromboembolism: a long-term follow-up study of Swedish men. J Thromb Haemost 6(4):558-564. https://doi.org/10.1111/j.1538-7836.2007. 02857.x (Epub 2007 Nov 27)

49. Isma N, Svensson PJ, Gottsäter A, Lindblad B (2009) Prospective analysis of risk factors and distribution of venous thromboembolism in the population-based Malmö Thrombophilia Study (MATS). Thromb Res 124(6):663-666

50. Petrauskiene V, Falk M, Waernbaum I, Norberg M, Eriksson JW (2005) The risk of venous thromboembolism is markedly elevated in patients with diabetes. Diabetologia 48:1017-1021

Publisher's Note Springer Nature remains neutral with regard to jurisdictional claims in published maps and institutional affiliations. 